\title{
QUEEN'S
UNIVERSITY
BELFAST
}

\section{Evaluation of the anisotropic mechanical properties of reinforced polyurethane foams}

Hamilton, A. R., Thomsen, O. T., Madaleno, L. A. O., Rosgaard Jensen, L., Rauhe, J. C. M., \& Pyrz, R. (2013). Evaluation of the anisotropic mechanical properties of reinforced polyurethane foams. Composites Science and Technology, 87, 210-217. https://doi.org/10.1016/j.compscitech.2013.08.013

\section{Published in:}

Composites Science and Technology

\section{Document Version:}

Peer reviewed version

\section{Queen's University Belfast - Research Portal:}

Link to publication record in Queen's University Belfast Research Portal

\section{Publisher rights}

(c) 2015, Elsevier. Licensed under the Creative Commons Attribution -NonCommercial-NoDerivs License

(https://creativecommons.org/licenses/by-nc-nd/4.0/), which permits distribution and reproduction for non-commercial purposes, provided the author and source are cited.

\section{General rights}

Copyright for the publications made accessible via the Queen's University Belfast Research Portal is retained by the author(s) and / or other copyright owners and it is a condition of accessing these publications that users recognise and abide by the legal requirements associated with these rights.

Take down policy

The Research Portal is Queen's institutional repository that provides access to Queen's research output. Every effort has been made to ensure that content in the Research Portal does not infringe any person's rights, or applicable UK laws. If you discover content in the Research Portal that you believe breaches copyright or violates any law, please contact openaccess@qub.ac.uk. 


\section{Evaluation of the Anisotropic Mechanical Properties of Reinforced Polyurethane Foams}

Andrew R. Hamilton ${ }^{\mathrm{a}, 1 *}$, Ole Thybo Thomsen ${ }^{\mathrm{b}, \mathrm{a}}$, Liliana A. O. Madaleno ${ }^{\mathrm{a}}$, Lars Rosgaard Jensen $^{\mathrm{a}}$, Jens Christian M. Rauhe ${ }^{\mathrm{a}}$, Ryszard Pyrz ${ }^{\mathrm{a}}$

${ }^{a}$ Department of Mechanical and Manufacturing Engineering, Aalborg University, Fibigerstræde 16, 9200 Aalborg East, Denmark

${ }^{b}$ Faculty of Engineering and the Environment, University of Southampton, Highfield, Southampton, SO17 1BJ, UK

* Corresponding author e-mail address: a.hamilton@qub.ac.uk

Telephone: +44 (0)289097 4116

Keywords: A. Particle-reinforced composites, A. Nano composites, B. Porosity/Voids, C. Elastic properties, Cellular materials

\section{$1 \quad$ Abstract}

2 The mechanical impact of adding milled glass fibers and nanoparticles at different mass fractions

3 to low-density (relative density $<0.2)$ polyurethane $(\mathrm{PU})$ foams is investigated. Tensile,

4 compressive, and shear stress-strain curves are measured in the plane parallel to the foam-rise

5 direction and the in-plane components of the elastic modulus are determined in order to assess

6 the mechanical anisotropy of the foams. Power-law relationships between the moduli and

7 apparent density are established for pure PU foams and used as a baseline to which the properties

8 of composite foams are compared. Cellular mechanics models based on both rectangular and

9 Kelvin unit-cell geometries are employed to estimate changes in the cell shape based on the

10 mechanical anisotropy of composite foams, and the model results are compared with direct

11 observations of the cellular structure from microscopy. A single measure of foam stiffness

12 reinforcement is defined that excludes the effects of the apparent foam density and cell shape.

13 The analysis reveals the large impact of cell shape on the moduli of the glass-fiber and

14 nanocomposite foams. Nanocomposite foams exhibit up to an $11.1 \%$ degree of reinforcement,

15 and glass-fiber foams up to $18.7 \%$ using this method for quantifying foam reinforcement,

16 whereas a simple normalization to the in-plane modulus components of the pure PU foam would

\footnotetext{
${ }^{1}$ Present address: School of Mechanical and Aerospace Engineering, Queen's University Belfast, Ashby Building, Stranmillis Road, Belfast BT9 5AH, Northern Ireland.
} 
17 indicate from $-40.5 \%$ to $25.9 \%$ reinforcement in nanocomposite foams, and -7.5 to $20.2 \%$ in

18 glass-fiber foams.

\section{1. Introduction}

20 Cellular materials are widely used in the energy and transport industries as lightweight structural

21 materials, most notably as the core material in structurally-efficient sandwich panels. Even in

22 nonstructural applications, like packaging or insulation, the mechanical performance and

23 integrity of these materials can be critical. Reinforcing polymer foams with short-fiber or

24 particulate additives is a potential route to improve the mechanical properties, and reduce the

25 weight and cost of these materials. Polyurethane (PU) foams are excellent candidates for

26 targeting mechanical improvement via reinforcement because the mechanical properties of PU

27 foams are relatively poor, and yet the cost and availability compare favorably with alternative

28 foams and natural products (e.g. polyvinylchloride foams and balsa wood).

29 The mechanical properties of cellular materials are highly dependent upon the cellular structure

30 of the foam, as well as the properties of the solid material making up the foam, both of which

31 may be influenced by reinforcing additives. One of the most important features of the cellular

32 structure in terms of mechanical properties is the void fraction, which is typically characterized

33 by the relative density $\left(\rho_{\mathrm{f}} / \rho_{\mathrm{s}}\right)$ - defined as the ratio of the density of the foam to that of the bulk

34 material of which the foam is constituted. In foams with a low relative density $\left(\rho_{\mathrm{f}} / \rho_{\mathrm{s}}<0.4\right)$,

35 many of the mechanical properties can be related to the relative density according to a power law

36 of the form [1]:

37

$$
\frac{P_{\mathrm{f}}}{P_{\mathrm{s}}}=C\left(\frac{\rho_{\mathrm{f}}}{\rho_{\mathrm{s}}}\right)^{n}
$$

38 where $P$ is the mechanical property of interest, $\rho$ is density, the parameters $C$ and $n$ depend on

39 the property of interest and the particulars of the foam (including the foam microstructure and 
40 deformation mode) $[2,3,4]$, and the subscripts $\mathrm{s}$ and $\mathrm{f}$ indicate the properties of the fully dense

41 solid and of the foam, respectively.

42 The exponent, $n$, in Equation (1) typically ranges from $1<n<2$ for the elastic moduli. A value

43 of $n=2$ corresponds to a bending-dominated deformation mode, which is typical of open-cell

44 foams with no cell walls. A value of $n=1$ corresponds to stretch-dominated deformation, as

45 might occur in a lattice with members oriented in the direction of loading. Intermediate values of

$46 n$ are typical in closed-cell foams, which have cell walls that undergo stretching and struts that

47 undergo bending.

48 Another important attribute for the mechanical properties of cellular materials is the cell shape.

49 In both synthetic and natural cellular materials it is typical for the cell shape to be elongated,

50 leading to anisotropic material properties [1]. The cells of polymer foams tend to be elongated in

51 the direction of foaming (also referred to as the foam rise direction), as shown in Figure 1(a).

52 Mechanical models based on an elongated unit cell have been developed to capture this

53 anisotropic behavior. Huber \& Gibson [5] considered a rectangular unit cell (Figure 1(b)) with a

54 cell shape anisotropy ratio, $R$, defined as:

55

$$
R=\frac{h}{l}
$$

56 where $h$ and $l$ are the dimensions of the unit cell parallel and perpendicular to the direction of

57 elongation, respectively, as shown in Figure 1(a). This rectangular-cell model predicts

58 transversely isotropic material properties that may be calculated using Equation (1) with an

59 additional term that is related to the shape anisotropy:

60

$$
\frac{P_{\mathrm{f}}}{P_{\mathrm{s}}}=C\left(\frac{\rho_{\mathrm{f}}}{\rho_{\mathrm{s}}}\right)^{n} f(R)
$$

61 where $f(R)$ is one of several functions of the shape anisotropy ratio of the unit cell, which are

62 tabulated for the moduli in different material directions in Table 1. According to this model, the 
63 mechanical properties increase in the direction of foaming $(1)$ and decrease in all other directions

64 as the shape anisotropy, $R$, increases. Using Equation (3), the cell shape anisotropy may be

65 calculated by taking the ratio of the foam moduli in different directions, for example:

$$
\frac{E_{1}}{E_{2}}=\frac{E_{1}}{E_{3}}=\frac{2 R^{2}}{1+(1 / R)^{3}},
$$

where $E_{1}, E_{2}$, and $E_{3}$ are the foam moduli in the material directions defined in Figure 1(a).

The tetrakaidecahedron introduced by Kelvin [6], shown in Figure 1(c), is an alternative cell geometry that is a closer representation of the cellular structure observed in polymer foams than the rectangular cell of Huber \& Gibson. In addition to the term $R$, the Kelvin cell requires a second term, $Q$, to uniquely define the geometry [7]. The impact of varying the parameter $Q$ on the cell geometry is illustrated in Figure 1(c). The full set of equations for the transversely

73 isotropic material properties as functions of $P_{\mathrm{s}}, \rho_{\mathrm{f}}, \rho_{\mathrm{s}}, R$, and $Q$ are published elsewhere [7,8].The

74 equivalent expression to Equation (4) using this alternative cellular geometry is:

$$
\frac{E_{1}}{E_{2}}=\frac{E_{1}}{E_{3}}=\frac{R}{4}\left[\frac{\left(2 \widetilde{Q}^{2} R^{2}+\frac{64 Q^{3}}{\sqrt{16+\widetilde{Q}^{2} R^{2}}}\right) C_{1}+\frac{8 R \widetilde{Q}^{3} C_{2}\left(32+4 Q \sqrt{16+\widetilde{Q}^{2} R^{2}}\right)}{\left(4 Q+2 \sqrt{16+\widetilde{Q}^{2} R^{2}}\right)\left(16+\widetilde{Q}^{2} R^{2}\right)}\left(\frac{\rho_{\mathrm{f}}}{\rho_{\mathrm{s}}}\right)}{8 R^{3} \widetilde{Q}^{5}\left(\frac{20 \sqrt{3}-11 \pi}{2 \sqrt{3}-\pi}\right)}\right],
$$

76 where $\widetilde{Q}=2+\sqrt{2} Q, C_{1}=\sqrt{3}-\pi / 2$, and $C_{2}=\frac{20 \sqrt{3}-11 \pi}{2 \sqrt{3}-\pi}$ for a hypocycloid cross-section

77 [7]. Whereas the properties of the solid do not appear in Equation (4), the relative density is

78 included in Equation (5).

79 Numerous studies have reported improvements in the mechanical properties of polymer foams

80 reinforced with short fibers $[9,10,11,12,13]$, particles $[14,15,16,17,18]$, and nano-particles

$81[19,20,21,22]$, but relatively few have made use of cellular models to interpret the results of 
mechanical tests and to develop predictive tools. Barma et al. [15] related the foam stiffness $\left(E_{\mathrm{f}}\right)$

83 to the solid stiffness $\left(E_{\mathrm{s}}\right)$ and cell size in particle-reinforced foams at the same density. Saint-

84 Michel et al. [16] modeled reinforced foams with higher relative densities $\left(\rho_{\mathrm{f}} / \rho_{\mathrm{s}}>0.3\right)$ as a

85 porous composite filled with closed, isolated, spherical voids. Zhang et al. [20] used a Mori-

86 Tanaka model to account for carbon nanotube reinforcement and cellular voids [23]. Goods et al.

87 [14] used a cellular model in the form of Equation (1) to describe the foam modulus $\left(E_{\mathrm{f}}\right)$ of PU

88 foams reinforced with metal particles, along with the Kerner equation to account for changes in

89 the solid modulus $\left(E_{\mathrm{s}}\right)$; others have taken a similar approach with various composite models to

90 estimate $E_{\mathrm{s}}$ for different materials [13,17,21,22]. The effect of additives on mechanical

91 anisotropy has been reported in several studies on chopped aramid and glass fibers [10,11,12],

92 but was only qualitatively attributed to a combination of cell shape $(R)$ and preferential fiber-

93 alignment. Sorrentino et al. [18] reported mechanical anisotropy in foams reinforced with iron

94 particles aligned in a magnetic field, which the authors attributed wholly to the reinforcement

95 and not to cell shape. Nano-scale fillers are known to influence the foaming process by inducing

96 bubble nucleation [19] and have been reported to affect the cell shape [24], yet despite the

97 potential influence of nanoparticles on cellular structure, mechanical anisotropy is often

98 overlooked in the analysis of reinforcement in nanocomposite foams.

99 A complete picture of the effect of reinforcement on the mechanical properties of composite

100 foams requires mechanical characterization in multiple material directions, and the consideration

101 of these factors related to cellular structure that may be affected by reinforcing additives. In this

102 paper, low-density polyurethane foams $\left(\rho_{\mathrm{f}} / \rho_{\mathrm{s}}<0.2\right)$ are characterized in tension and compression

103 in two principal material directions and in shear using a modified Arcan testing fixture [25].

104 Power-law relationships between the in-plane moduli and density are established for pure PU

105 foams to compensate for density effects in the comparison between composite and pure PU

106 foams. The modulus data are used in conjunction with cellular material models to make 
predictions about the cellular structure of the foams that are compared with microscopic

108 observations. Changes in the moduli of composite foams are attributed to changes in the cellular

109 structure (relative density, and cell shape) and to changes in the solid properties $\left(\rho_{\mathrm{s}}, E_{\mathrm{s}}\right)$, and a

110 definition for the degree of foam reinforcement is proposed that is independent of cellular

111 structure and that takes into account the tradeoff between stiffness and density in the mechanical

112 performance of foams.

\section{2. Materials and methods}

\section{$114 \quad 2.1$ Foam Preparation}

115 Rigid, closed-cell PU foams and the precursor components for producing these foams

116 (methylene diphenyl diisocyanate and polyol blends) were obtained from the industrial producer,

117 Recticel $^{2}$. Pure PU foams (with no particle reinforcement) were obtained from the manufacturer

118 in a range of densities $\left(\rho_{\mathrm{f}}=128.0,153.8,163.4 \mathrm{~kg}-\mathrm{m}^{-3}\right)$, and were also produced in the lab under

119 the same conditions as composite foams $\left(\rho_{\mathrm{f}}=144.5 \mathrm{~kg}-\mathrm{m}^{-3}\right)$.

120 Montmorillonite-carbon nanotube hybrid nanoparticles were produced by chemical vapour

121 deposition (CVD) onto iron modified montmorillonite [26]. The pre-exfoliated morphology of

122 these hybrid nanoparticles has been observed to result in good dispersion within polymer

123 matrices [27]. Nanocomposite PU foams were prepared by incorporating these hybrid

124 nanoclay/carbon-nanotube particles into the polyol blend before the foaming process, which

125 resulted in better dispersion than incorporation into the diisocyanate, . Prior to use, the hybrid

126 nanoparticles were dried at $110{ }^{\circ} \mathrm{C}$ for $24 \mathrm{~h}$ in order to remove any water. The hybrid particles

127 were dispersed in the polyol blend at $0.25,0.5$, and $1.0 \mathrm{wt} \%$ using a lab homogenizer operating

128 at $3500 \mathrm{rpm}$ for $150 \mathrm{~min}$ in an ice bath. The mixture of hybrids dispersed in the polyol was added

129 to the diisocyante and stirred at $3000 \mathrm{rpm}$ for $25 \mathrm{~s}$. The resulting mixture was quickly poured into

130 a mold and allowed to foam freely in one direction. The resulting foam was cured for $24 \mathrm{~h}$ at

\footnotetext{
${ }^{2}$ Recticel N.V. - IDC Corporate, Damstraat 2, B-9230 Wetteren, Belgium.
} 
room temperature and atmospheric pressure. The average density of these nanocomposite foams

132 ranged from $105.3-112.1 \mathrm{~kg}-\mathrm{m}^{-3}$. The tendency for nanocomposite foams to have lower densities

133 as compared with the lab-produced pure foams has been reported previously [4] and may be

134 explained by the high surface area of the nano-filler and the effects this can have on bubble

135 nucleation and growth during foaming [19].

136 Milled glass fibers with an average size of 230 microns were obtained from R\&G

137 Faserverbundwerkstoffe $\mathrm{GmbH}^{3}$. Glass-fiber composite foams were produced with 1.0, 3.0, 5.0,

$1387.0,9.0,11.0,13.0,15.0,17.0$, and $19.0 \mathrm{wt} \%$ glass fibers. Because the volume of polyol was

139 insufficient to accommodate these high loadings of reinforcement, the glass fibers were

140 dispersed into the diisocyanate using a lab homogenizer operating at $1450 \mathrm{rpm}$ for $5 \mathrm{~min}$. The

141 polyol was premixed at $2850 \mathrm{rpm}$ for $25 \mathrm{~s}$ using the homogenizer. The glass-fiber-diisocyanate

142 mixture was cooled to room temperature and added to the premixed polyol and stirred at 2850

$143 \mathrm{rpm}$ rpm for $25 \mathrm{~s}$. The resulting mixture was quickly poured into a mold and allowed to foam

144 freely in one direction. The resulting foam was cured for $24 \mathrm{~h}$ at room temperature and

145 atmospheric pressure. The average density of the resulting glass-fiber foams ranged from 131.7-

$146207.5 \mathrm{~kg}-\mathrm{m}^{-3}$. The tendency for glass-fiber foams to have higher densities as compared with the

147 lab-produced pure foams can be attributed to the higher initial density of the glass-fiber-

148 diisocyanate mixture (especially at the higher filler fractions), which could be expected to hinder

149 foam cell growth.

$150 \quad 2.2$ Mechanical Testing

151 Mechanical tests were conducted using a modified Arcan fixture (MAF) [25], which allows the

152 application of tensile, compressive, shear, biaxial tensile-shear, or biaxial compressive-shear

153 loads through the spiral configuration of loading holes shown in Figure 2(a). The non-standard

\footnotetext{
${ }^{3}$ R\&G Faserverbundwerkstoffe GmbH, Postfach 1145, D-71107 Waldenbuch, Germany.
} 
154 compact specimen geometries shown in Figure 2(b) were adopted from Taher et al. [25], and

155 were produced using a CNC router. Shear specimens were manufactured with the foam rise

156 direction in the plane of the applied shear (1-2 plane). Tension and compression specimens were

157 either oriented with the axis of loading oriented parallel (1-direction, designated 'rise') or

158 perpendicular (2- and 3-directions, designated 'transverse') to the foam rise direction.

159 Testing was performed at a displacement rate of $0.6 \mathrm{~mm} / \mathrm{min}$. on a screw-driven load frame with

160 a $2 \mathrm{kN}$ load transducer to record force data. The state of strain on the front and back surfaces of

161 the specimen was measured by digital image correlation (DIC) [28,29], which was performed

162 using an Aramis metrology system (GOM mbH). Digital images had a typical resolution of

$16310 \mu \mathrm{m} /$ pixel and were acquired at regular intervals throughout testing. Image correlation was

164 performed using a window/facet size of $60 \times 60$ pixels and a step size of 30 pixels. These

165 parameters were selected because, at $>1.5$ times the average cell size of the foams being tested,

166 the window size was sufficiently large to yield a relatively homogeneous strain field (strain

167 variation on the size scale of individual foam cells was not of interest in this study). Repeated

168 analyses with window sizes ranging from 10-80 pixels square yielded no significant differences

169 in the resulting stress-strain curves. Representative full-field strain measurements are shown in

$170 \quad$ Figure 3 for each specimen type while loaded in the elastic range.

171 Stress-strain curves were constructed by averaging the strain data within the gauge area or along

172 the gauge line on both the front and back surfaces of each specimen type (indicated in Figure

173 2(b)), and computing the nominal stress from the load data associated with each image. The

174 strain data were corrected both for non-uniformity within the gauge zone and for surface effects

175 using models of each specimen type in the commercial finite element (FE) code Abaqus 6.10-2.

176 The results of this FE analysis for the shear specimen indicate a small variation in the shear

177 strain along the gauge line (approx. 5\%, as shown in Figure 4(a)), and a larger variation on the 
178 gauge plane through the specimen thickness (approx. 20\%, as shown in Figure 4(b)). Similar

179 analyses were conducted for tensile and compressive specimens, and correction factors were

180 computed from the FE results to scale the average surface strain in the gauge (the quantity

181 measured by DIC) to the average through-thickness gauge strain, as described by Taher, et al.

182 [25]. This methodology has been shown to compensate for errors associated with non-uniform

183 strain distributions arising from the specimen geometry [30]. Specimen dimensions that are not

184 sufficiently large compared to the cell size are another potential source of experimental error in

185 evaluating the elastic moduli of foams, but the specimens in this work are sufficiently large to

186 avoid this effect according to Tekog lu et al. [31] and given the cell sizes presented in Table 2.

187 3. Results and Discussion

188 3.1 Mechanical Characterization of Pure PU Foams

189 Representative tensile, compressive, and shear stress-strain curves for pure PU foam are shown

190 in Figure $5\left(\rho_{\mathrm{f}}=128.0 \mathrm{~kg}-\mathrm{m}^{-3}\right)$. The tensile and compressive moduli in the rise direction of the

191 foam are higher than those in the transverse direction, indicating orthotropic material properties

192 due to an elongated cell shape in the rise direction. The moduli are plotted as a function of

193 density for all pure PU foams in Figure 6, and power law curves in the form of Equation (3) are

194 fitted to the experimental data.

195 3.2 Mechanical Characterization of Composite PU Foams

196 The results of tensile and shear testing of glass-fiber and nanocomposite foams are plotted as a

197 function of density in Figure 7 along with the trend lines for pure PU foams. Nanocomposite

198 foams were also tested in compression and exhibited moduli similar to those in tension. The

199 elastic moduli of the composite foams vary considerably from that of the lab-produced pure PU

200 foam $\left(\rho_{\mathrm{f}}=144.5 \mathrm{~kg}-\mathrm{m}^{-3}\right)$, but the power law trend for pure PU foams in Figure 7 indicates that

201 much of this variation can be attributed to changes in the density of the composite foams. 
The modulus data for composite foams is normalized to the trends with density for pure PU

203 foams and plotted as a function of filler content in Figure 8. The normalized moduli would all

204 equal one if the changes in stiffness of the composite foams were solely attributable to changes

205 in density. Figure 8(a) and (b) highlights the tendency for $E_{1}$ to increase and for $E_{2}$ to decrease in

206 nanocomposite foams compared with the pure PU foam trend. Glass-fiber composite foams

207 exhibit a less-pronounced increase in $E_{1}$ and decrease in $E_{2}$ up to a fiber content of $11 \mathrm{wt} \%$,

208 beyond which the normalized moduli tend to all increase by approximately the same amount.

2093.3 Mechanical and Cell Shape Anisotropy

210 Considered separately, the moduli of composite foams suggest varying degrees of mechanical

211 reinforcement: the rise-direction tensile modulus implies a 4-26\% increase, while the transverse

212 tensile modulus implies as much as a $40 \%$ decrease. The changes in the degree of mechanical

213 anisotropy $\left(E_{1} / E_{2}\right)$ corresponding to these divergent trends in the tensile moduli indicate that

214 changes in the cell shape may account for some or all of these mechanical deviations from the

215 pure PU trend.

216 The cellular microstructure of the lab-produced pure PU $\left(\rho_{\mathrm{f}}=144.5 \mathrm{~kg}-\mathrm{m}^{-3}\right)$ and composite

217 foams was investigated using scanning electron microscopy. The average cell sizes were

218 measured both in the foam rise and transverse directions according to ASTM standard 3576 [32],

219 and are presented in Table 2. The values of shape anisotropy ratio plotted in Figure 9 were

220 calculated as the ratio of these average dimensions. The cell shape anisotropy was also calculated

221 using the ratio of the Young's moduli $\left(E_{1} / E_{2}\right)$ and Equations (4) or (5) from the rectangular and

222 Kelvin unit-cell material models, respectively. The Kelvin-cell model (Equation (5)) has the

223 additional geometry parameter, $Q$, which was used to fit the predicted value of $R$ to the observed

224 value for the pure PU foam. Estimating the solid PU density $\left(\rho_{\mathrm{s}}\right)$ to be $1200 \mathrm{~kg}-\mathrm{m}^{3}[1,33]$, a value

225 of $Q=0.5755$ was empirically determined to result in the same value of $R$ that was measured for

226 the pure PU foam. These values of $Q$ and $\rho_{\mathrm{s}}$ that were determined for the pure PU foam were 
227 also used to calculate $R$ for composite foams and resulted in reasonable agreement between the

228 predicted and observed values, as shown in Figure 9, in which both the measured and the

229 predicted values of shape anisotropy are plotted as a function of filler type and filler content. The

230 values of shape anisotropy measured for pure PU ( $\left.R_{\text {measured }}\right)$, and predicted for pure PU using the

231 two cellular models $\left(R_{\text {rectangular }}\right.$ and $\left.R_{\text {Kelvin }}\right)$ are designated with horizontal lines for comparison

232 with composite foams. The predicted shape anisotropy ratios resulting from the two different

233 cellular models in Figure 9 exhibit similar trends with filler content, but the Kelvin-cell model

234 values are shifted up by an approximately constant amount of 0.4 from the rectangular-cell

235 model values and are in better agreement with the measured values, which can be attributed to

236 the additional parameter $Q$ in the Kelvin model. The cell shape for glass-fiber composites is only

237 slightly changed from that of the pure PU foam (within 8\%), but $R$ increases significantly for

238 nanocomposite foams (up to 33\%). This larger effect of nano-fillers on the cell shape is

239 consistent with the greater influence of nano-particles on bubble nucleation reported in the

240 literature [19].

2413.4 Degree of Mechanical Reinforcement

242 The degree of stiffness reinforcement in composite foams was evaluated as the relative

243 difference between the elastic moduli of composite foams, and the predicted moduli of a

244 hypothetical pure PU foam with the same density and cell shape as the composite foam of

245 interest. This measure of foam reinforcement was calculated by rearranging Equation (3) into the

246 following form:

$$
E_{\mathrm{f}}=\left[\frac{C E_{\mathrm{s}}}{\left(\rho_{\mathrm{s}}\right)^{n}}\right]\left(\rho_{\mathrm{f}}\right)^{n} f(R) .
$$

248 The ratio of Equation (6) written for a composite foam (with terms subscripted 'comp') and for a

249 pure polymer foam (terms subscripted 'pure') yields the expression 


$$
\frac{\left(E_{\mathrm{f}}\right)_{\text {comp }}}{\left(E_{\mathrm{f}}\right)_{\text {pure }}}=\left[\frac{\left(E_{\mathrm{s}} /\left(\rho_{\mathrm{s}}\right)^{n}\right)_{\text {comp }}}{\left(E_{\mathrm{s}} /\left(\rho_{\mathrm{s}}\right)^{n}\right)_{\text {pure }}}\right]\left(\frac{\left(\rho_{\mathrm{f}}\right)_{\text {comp }}}{\left(\rho_{\mathrm{f}}\right)_{\text {pure }}}\right)^{n} \frac{f\left(R_{\text {comp }}\right)}{f\left(R_{\text {pure }}\right)}
$$

which may be rearranged into:

$$
\left(E_{\mathrm{f}}\right)_{\text {comp }}=\frac{\left(E_{\mathrm{f}}\right)_{\text {pure }}}{\left(\left(\rho_{\mathrm{f}}\right)_{\text {pure }}\right)^{n}}\left(\left(\rho_{\mathrm{f}}\right)_{\text {comp }}\right)^{n} \frac{f\left(R_{\text {comp }}\right)}{f\left(R_{\text {pure }}\right)}\left[\frac{\left(E_{\mathrm{s}} /\left(\rho_{\mathrm{s}}\right)^{n}\right)_{\text {comp }}}{\left(E_{\mathrm{s}} /\left(\rho_{\mathrm{s}}\right)^{n}\right)_{\text {pure }}}\right]
$$

253 The constant terms and exponents in the equations for the power-law curves in Figure 6(a) were

254 substituted for the term $\frac{\left(E_{\mathrm{f}}\right)_{\text {pure }}}{\left(\left(\rho_{\mathrm{f}}\right)_{\text {pure }}\right)^{n}}$ and the exponent $n$, respectively, and the term

$255\left[\frac{\left(E_{\mathrm{s}} /\left(\rho_{\mathrm{s}}\right)^{n}\right)_{\text {comp }}}{\left(E_{\mathrm{s}} /\left(\rho_{\mathrm{s}}\right)^{n}\right)_{\text {pure }}}\right]$ was defined as $\Gamma$, the degree of foam reinforcement, to yield:

$$
\left(E_{1}\right)_{\text {comp }}=4.495 \times 10^{-2}\left(\left(\rho_{\mathrm{f}}\right)_{\text {comp }}\right)^{1.556}\left[\frac{f\left(R_{\text {comp }}\right)}{f\left(R_{\text {pure }}\right)}\right] \Gamma,
$$

258 and

$$
\left(E_{2}\right)_{\text {comp }}=1.831 \times 10^{-2}\left(\left(\rho_{\mathrm{f}}\right)_{\text {comp }}\right)^{1.634}\left[\frac{f\left(R_{\text {comp }}\right)}{f\left(R_{\text {pure }}\right)}\right] \Gamma \text {, }
$$

$$
\left(G_{12}\right)_{\text {comp }}=3.509 \times 10^{-3}\left(\left(\rho_{\mathrm{f}}\right)_{\text {comp }}\right)^{1.810}\left[\frac{f\left(R_{\text {comp }}\right)}{f\left(R_{\text {pure }}\right)}\right] \Gamma .
$$

The reinforcement term, $\Gamma$, is the ratio of solid stiffness of the composite and pure materials, each normalized by the corresponding solid density raised to the power $n$, and accounts for the relative difference between the properties of a composite foam and those of a pure foam with the

263 same density and cell shape. This definition of foam reinforcement requires that the stiffness of

264 the composite material $\left(\left(E_{\mathrm{s}}\right)_{\text {comp }}\right)$ increase relative to its density by at least as much as does the

265 pure foam (i.e. according to a power law with exponent $n$ ) in order to achieve positive

266 reinforcement $(\Gamma>1)$. This is an appropriate measure of reinforcement for cellular materials

267 because an increase in solid stiffness $\left(E_{\mathrm{s}}\right)$ that is equal to the $n$-power law trend with solid

268 density $\left(\rho_{\mathrm{s}}\right)$ could be realized by simply reducing the void content of the pure material, and so is

269 not considered reinforcement of the foam. $\Gamma$ is assumed to be independent of the material 
270 direction in Equations (9-10) because the good agreement between the measured and the

271 predicted shape anisotropy (using the Kelvin model) of composite foams implies that the

272 mechanical anisotropy can be wholly attributed to cell-shape effects. If cellular models had been

273 unable to accurately predict $R$ for composite foams, then multiple direction-dependent $\Gamma$ terms

274 could be used in Equations (9-11) to account for factors leading to anisotropy of the solid

275 composite $\left(\left(E_{\mathrm{s}}\right)_{\text {comp }}\right)$, e.g. preferential fiber orientation.

276 The functions $f(R)$ in Equations (9-11) were taken from Table 1 for the rectangular-cell model

277 and from the literature for the Kelvin-cell model ${ }^{4}[7,8]$, and the calculated values of shape

278 anisotropy from the corresponding cellular model (presented in Figure 9) were used. The

279 reinforcement term, $\Gamma$, was determined by minimizing the squared-error between the measured

280 moduli and the moduli predicted using Equations (9-11) for each composite foam, and is plotted

281 for glass-fiber and nanocomposite foams in Figure 10. The normalized moduli calculated using

282 the best-fit values of $\Gamma$ are shown along with the measured values in Figure 8 . The predicted

283 values are in good agreement with the measured moduli for glass-fiber composite foams

284 regardless of the cellular model employed (predicted values are mostly within one standard

285 deviation of the measured value). However, the rectangular cellular model cannot simultaneously

286 predict the in-plane moduli accurately for nanocomposite foams. This failure of the rectangular-

287 cell model is shown in Figure 8(a) and (c), in which the predicted values of $E_{l}$ are about one

288 standard deviation above and of $G_{12}$ are up to 4 standard deviations below the measured values

289 for nanocomposite foams. The Kelvin-cell model predictions, which are also shown in Figure 8,

290 are in good agreement with measured values (all within one standard deviation). This is

291 consistent with the poor predictions of $R$ resulting from the rectangular-cell model in Figure 9.

\footnotetext{
${ }^{4}$ The terms related to cellular structure $(R, Q)$ cannot be isolated from the other terms in the expressions for the foam moduli in the Kelvin-cell model. Consequently, the ratio $f\left(R_{\text {comp }}\right) / f\left(R_{\text {pure }}\right)$ had to be computed numerically as $E_{\mathrm{f}}\left(R_{\text {comp }}, Q,\left(\rho_{\mathrm{f}}\right)_{\text {comp }}, \rho_{\mathrm{s}}\right) / E_{\mathrm{f}}\left(R_{\text {pure }}, Q,\left(\rho_{\mathrm{f}}\right)_{\text {comp }}, \rho_{\mathrm{s}}\right)$ for each composite foam. In all cases, a value $Q=0.5755$ and $\rho_{\mathrm{s}}=1.2$ $\mathrm{kg}-\mathrm{m}^{-3}$ was used.
} 
292 The adequacy of the rectangular-cell model for characterizing the glass-fiber foam properties,

293 despite the large difference between the measured and predicted values of $R$ using this model

294 (Figure 9), is likely due to the relatively small change in cell shape (and consequently the small 295 mechanical impact of cell shape) in these foams.

296 The degree of foam reinforcement for glass-fibers shown in Figure 10 is similar regardless of the 297 cellular model used. The values of $\Gamma$ from the two cellular models are most divergent in foams

298 with the largest changes in $R$ compared to the pure foam (1.0, 3.0, 5.0, 9.0, and $19.0 \mathrm{wt} \%$ milled 299 glass fibers), in which cases the values produced using the Kelvin-cell model are recommended 300 by the more accurate predicted values of $R$ from this model. There is a relatively small degree of 301 foam reinforcement (2.8-10.7\% increase) in foams with $1.0-11.0 \mathrm{wt} \%$ glass-fibers, which is the 302 same range of filler content over which $E_{1}$ increased while $E_{2}$ decreased compared with the pure 303 PU foam trend in Figure 8 (a) and (b). The changes in the normalized moduli over this range of 304 filler content are largely attributable to the mechanical effects of cell shape, $R$, rather than 305 stiffening of the solid material. Above a glass-fiber content of $11.0 \mathrm{wt} \%, E_{1}$ and $E_{2}$ tended to rise 306 together relative to the pure PU trend, leading to more pronounced increases in the degree of 307 foam reinforcement (up to $18.7 \%$ ).

308 Nanocomposite foams offer a more extreme example of divergence in the normalized moduli $\left(E_{1}\right.$ 309 and $E_{2}$ ) than any of the glass-fiber foams, which may be attributed to the large increases in $R$ for 310 these foams (Figure 9). With $\Gamma$ changing by just 2.4 and $-2.4 \%$, the modulus changes in 0.25 and

$3111.0 \mathrm{wt} \%$ nanocomposite foams can be almost wholly attributed to changes in cellular structure.

312 The higher relative values of $E_{2}$ and $G_{12}$ for the $0.5 \mathrm{wt} \%$ nanocomposite foam resulted in the 313 larger increase in the degree of reinforcement of $11.1 \%$.

\section{4. Conclusions}

315 Composite PU foams with glass-fibers and hybrid nano-particles were fully characterized in the 316 plane parallel to foaming. The moduli of composite foams were normalized to the trends with 
317 density established for pure PU foams. The normalized moduli of composite foams in the foam

318 rise direction increased by $4-26 \%$, but increased less or even decreased by as much as $40 \%$ in

319 the transverse direction. These divergent trends were explained by the increased cell shape

320 anisotropy, which was predicted using cellular mechanics models and confirmed

321 microscopically. The mechanical model based on the Kelvin tetrakaidecahedron unit-cell was

322 favored based on its accurate predictions of cell shape for the specific foams in this study, but a

323 simpler rectangular unit-cell model predicted similar trends and may prove sufficiently accurate

324 for different foams. After accounting for the effects of density and cell shape, any remaining

325 mechanical difference in composite foams was attributed to changes in the properties of the solid

$326\left(E_{\mathrm{s}}, \rho_{\mathrm{s}}\right)$ through a quantity termed foam reinforcement $(\Gamma)$, which was shown to depend on both

327 the stiffness and the density of the solid composite. An isotropic $\Gamma$ was sufficient to accurately

328 predict the measured in-plane moduli of the foams in this study, but directionally-dependent

329 values of $\Gamma$ could be considered in cases when the composite solid stiffness $\left(\left(E_{\mathrm{s}}\right)_{\text {comp }}\right)$ is

330 dependent on the material direction, as may be the case for aligned fiber-reinforced foams.

331 The comparison of reinforced polymer foams with the corresponding pure foam at the same

332 foam density by establishing power-law trends for the pure foams allows a fair comparison

333 between materials with the same density. It should be noted that normalization of the foam

334 modulus to foam density, $E_{\mathrm{f}} / \rho_{\mathrm{f}}$, does not necessarily provide for the same comparison between

335 foams of unequal densities. The determination of cell shape contributions to mechanical

336 anisotropy is important for understanding the causes of property enhancement in a given material

337 direction (and the potential trade-offs in other directions), and is relevant for applications with

338 anticipated loads in multiple material directions. This is the case for sandwich panel core

339 materials, which typically experience multi-axial loading conditions in service. In conjunction

340 with composite models to predict the composite solid stiffness $\left(\left(E_{\mathrm{s}}\right)_{\mathrm{comp}}\right)$ and density $\left(\left(\rho_{\mathrm{s}}\right)_{\mathrm{comp}}\right)$, 
342 additives for foams in view of the potential tradeoff between stiffness and added weight.

\section{Acknowledgments}

344 This work was conducted and financially supported through EU FP7-NMP-2007-2.1-1 large

345 scale integrated project "NanCore", Grant Agreement No. 214148, and the Department of

346 Mechanical and Manufacturing Engineering, Aalborg University, Denmark. The authors

347 gratefully acknowledge Thomas Sørensen Quaade for his technical assistance, especially with

348 electron microscopy.

[1] Gibson LJ, Ashby MF. Cellular Solids Structure and Properties. Pergamon Press, Oxford (1988).

[2] Roberts AP, Garboczi EJ. Elastic moduli of model random three-dimensional closed-cell cellular solids. Acta Mater 2001;49:189-197.

[3] Roberts AP, Garboczi EJ. Elastic properties of model random three-dimensional open-cell solids. J Mech Phys Solids 2002;50:33-55.

[4] Istrate OM, Chen B. Relative modulus-relative density relationships in low density polymer-clay nanocomposite foams. Soft Matter 2011;7:1840-1848

[5] Huber AT, Gibson LJ. Anistropy of polymer foams. J Mater Sci 1988;23:3031-3040.

[6] Thomson,W. (Lord Kelvin). On the division of space with minimum partitional area. Phil Mag 1887;24:503-514.

[7] Sullivan RM, Ghosn LJ, Lerch BA. A general tetrakaidecahedron model for open-celled foams. Int J Solid Struct 2008;45:1754-1765.

[8] Sullivan RM, Ghosn LJ. Shear moduli for non-isotropic, open cell foams using a general elongated Kelvin foam model. Int J Eng Sci 2009;47:990-1001.

[9] Cotgreave TC, Shortall JB. The mechanism of reinforcement of polyurethane foam by high-modulus chopped fibres. J Mater Sci 1977;12:708.

[10] Shen H, Nutt S. Mechanical characterization of short fiber reinforced phenolic foam. Composites, Part A 2003;34:899-906.

[11] Desai A, Auad ML, Shen H, Nutt SR. Mechanical behavior of hybrid composite phenolic foam. J Cell Plast 2008;44:15-36

[12] Alonso MV, Auad ML, Nutt S. Short-fiber-reinforced epoxy foams. Composites, Part A 2006;37:1952-1960.

[13] Neagu RC, Cuénoud M, Berthold F, Bourban P-E, Gamstedt K, Lindström M, Månson J-AE. The potential of wood fibers as reinforcement in cellular biopolymers. J Cell Plast 2012;48:71-103.

[14] Goods SH, Neuschwanger CL, Whinnery LL, Nix WD. Mechanical properties of a particle-strengthened polyurethane foam. J Appl Polym Sci 1999;74:2724-2736.

[15] Barma P, Rhodes MB, Salovey R. Mechanical properties of particulate-filled polyurethane foams. J App Phys 1978;49:4985-

[16] Saint-Michel F, Chazeau L, Cavaillé J-Y. Mechanical properties of high density polyurethanefoams: II Effect of the filler size. Comp Sci Tech 2006;2709-2718.

[17] Yin B, Li Z-M, Quan H, Yang M-B, Zhou Q-M, Tian C-R, Wang J-H. Morphology and mechanical properties of nylon1010-filled rigid polyurethane foams. J Cell Plast 2004;36:333-349.

[18] Sorrentino L, Aurilia M, Forte G, Iannace S. Anisotropic mechanical behavior of magnetically oriented iron particle reinforced foams. J Appl Polym Sci 2011;119:1239-1247.

[19] Lee LJ, Zeng C, Cao X, Han X, Shen J, Xu G. Polymer nanocomposite foams. Comp Sci Tech 2005;65:2344-2363.

[20] Zhang L, Yilmaz ED, Schjødt-Thomsen J, Rauhe JC, Pyrz R. MWNT reinforced polyurethane foam: Processing, characterization and modelling of mechanical properties. Comp Sci Tech 2011;71:877-884.

[21] Yan D, Xu L, Chen C, Tang J, Ji X, Li Z. Enhanced mechanical and thermal properties of rigid polyurethane foam composites containing graphene nanosheets and carbon nanotubes. Polym Int 2012;61:1107-1114.[21] Lee LJ, Zeng C, Cao X, Han X, Shen J, Xu G. Polymer nanocomposite foams. Comp Sci Tech 2005;65:2344-2363.

[22] Istrate OM, Chen B, Relative modulus-relative density relationships in low density polymer-clay nanocomposite foams. Soft Matter 2011;7:1840-1848.

[23] Schjødt-Thomsen J, Pyrz R. Effective properties of cellular materials. Polm Eng Sci 2001;41:752-757. 
[24] Verdejo R, Bernal MM, Romasanta LJ, Tapiador FJ, Lopez-Manchado MA. Reactive nanocomposite foams. Cell Polym 2011;30:45-61.

[25] Taher ST, Thomsen OT, Dulieu-Barton JM, Zhang S. Determination of mechanical properties of PVC foam using a modified Arcan fixture. Composites, Part A 2012;43:1698-1708.

[26]Madaleno L, Pyrz R, Jensen LR, Pinto JJC, Lopes AB, Dolomanova V, Schjødt-Thomsen J, Rauhe JC. Synthesis of claycarbon nanotube hybrids: Growth of carbon nanotubes in different types of iron modified montmorillonite. Comp Sci Tech 2012;72:377-381.

[27] Madaleno L, Pyrz R, Crosky A, Jensen LR, Rauhe JC, Dolomanova V, Viegas de Barros Timmons AMM, Pinto JCC, Norman J. Processing and characterization of polyurethane nanocomposite foam reinforced with montmorillonite-carbon nanotube hybrids. Composites, Part A 2013;44:1-7.

[28] Peters WH, Ranson WF. Digital imaging techniques in experimental stress analysis. Opt Eng 1982;21:427-431.

[29] Chu TC, Ranson WF, Sutton MA. Applications of digital-image-correlation techniques to experimental mechanics. Exp Mech 1985;25:232-244.

[30] Zhang S, Dulieu-Barton J, Freuhmann RK, Thomsen OTT. A methodology for obtaining material properties of polymeric foam at elevated temperatures. Exp Mech 2012;52:3-15.

[31] Tekog lu C, Gibson LJ, Pardoen T, Onck PR. Size effects in foams: Experiments and modeling. Prog Mater Sci (2011) 56:109-138.

[32] ASTM 3576 - 04. Standard Test Method for Cell Size of Rigid Cellular Plastics. ASTM International, 100 Barr Harbor Drive, PO Box C700, West Conshohocken, PA 19428-2959, United States.

[33] Roff, W. F.; Scott, J. R. Fibres, Films, Plastics and Rubbers-A Handbook of Common Polymers, Butterworths:London, UK, 1971; p. 445. 
Table 1. The functions $f(R)$ from Equation (3) for the elastic moduli in each material direction, based on a rectangular unit cell.

\begin{tabular}{c|c}
\hline Property & $\boldsymbol{f ( R )}$ \\
\hline$E_{1}$ & $R$ \\
$E_{2}, E_{3}$ & $\frac{1}{2 R}\left[1+\left(\frac{1}{R}\right)^{3}\right]$ \\
$G_{12}, G_{13}$ & $\frac{2}{R(R+1)}$ \\
$G_{23}$ & $\frac{1}{R}$ \\
\hline
\end{tabular}

Table 2. Average cell dimensions measured in pure and nanocomposite PU foams.

\begin{tabular}{c|cc}
\hline Foam & $\boldsymbol{h}[\boldsymbol{\mu} \mathbf{m}]$ & $\boldsymbol{l}[\boldsymbol{\mu} \mathbf{m}]$ \\
\hline Pure PU (lab) & 389 & 250 \\
$0.25 \mathrm{wt} \%$ Nanocomposite & 317 & 182 \\
$0.5 \mathrm{wt} \%$ Nanocomposite & 357 & 214 \\
$1.0 \mathrm{wt} \%$ Nanocomposite & 340 & 197 \\
$1.0 \mathrm{wt} \%$ Glass-fiber & 387 & 249 \\
$3.0 \mathrm{wt} \%$ Glass-fiber & 372 & 231 \\
$5.0 \mathrm{wt} \%$ Glass-fiber & 458 & 268 \\
$7.0 \mathrm{wt} \%$ Glass-fiber & 370 & 227 \\
$9.0 \mathrm{wt} \%$ Glass-fiber & 346 & 230 \\
$11.0 \mathrm{wt} \%$ Glass-fiber & 360 & 204 \\
$13.0 \mathrm{wt} \%$ Glass-fiber & 297 & 205 \\
$15.0 \mathrm{wt} \%$ Glass-fiber & 368 & 223 \\
$17.0 \mathrm{wt} \%$ Glass-fiber & 386 & 231 \\
$19.0 \mathrm{wt} \%$ Glass-fiber & 349 & 215 \\
\hline
\end{tabular}


(a)

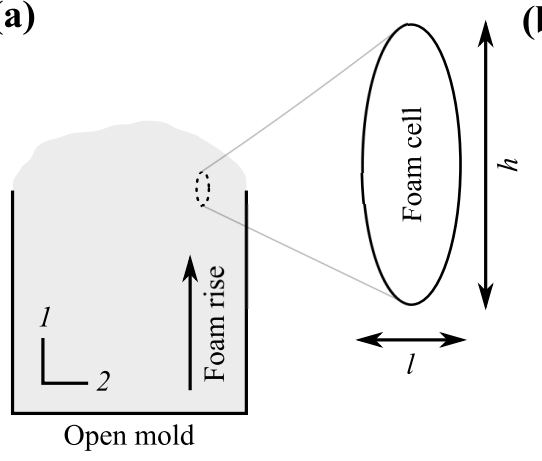

(b)

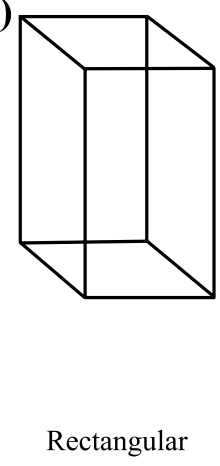

(c)

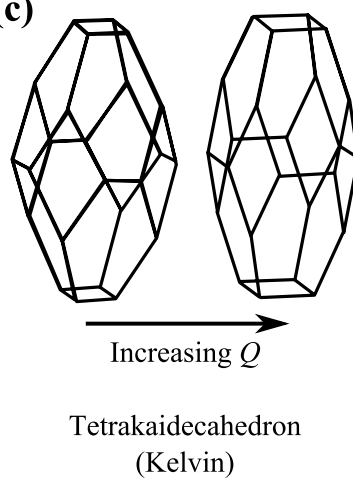

Figure 1. (a) Schematic of polyurethane foaming process with material coordinate system specified, and inset showing a typical elongated cell geometry with dimensions. Cell shape geometries for (b) rectangular, and (c) Kelvin cellular mechanical models (Reproduced and adapted from [8] with permission from Elsevier).

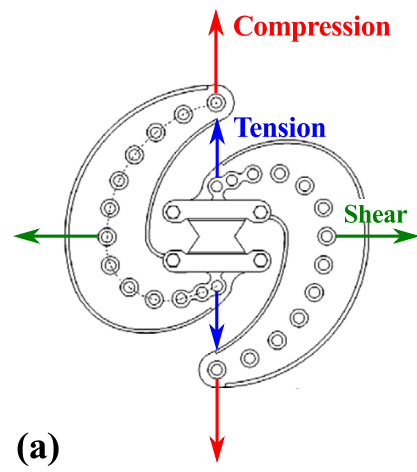

Figure 2. (a) Schematic of modified Arcan fixture, with tensile, compressive, and shear loading
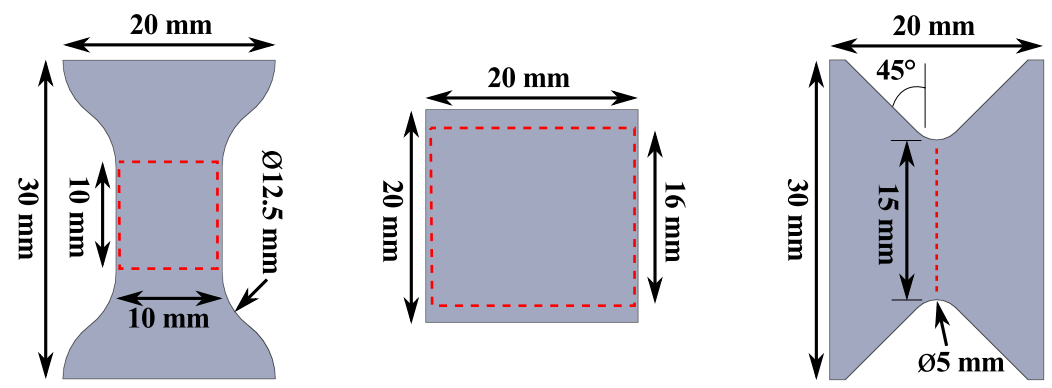
configurations specified (Reproduced and adapted from [25] with permission from Elsevier). (b) Specimen geometries for tension, compression, and shear loading configurations (all specimen thicknesses $15 \mathrm{~mm}$ ). Gauge area/line indicated by dashed red lines. 

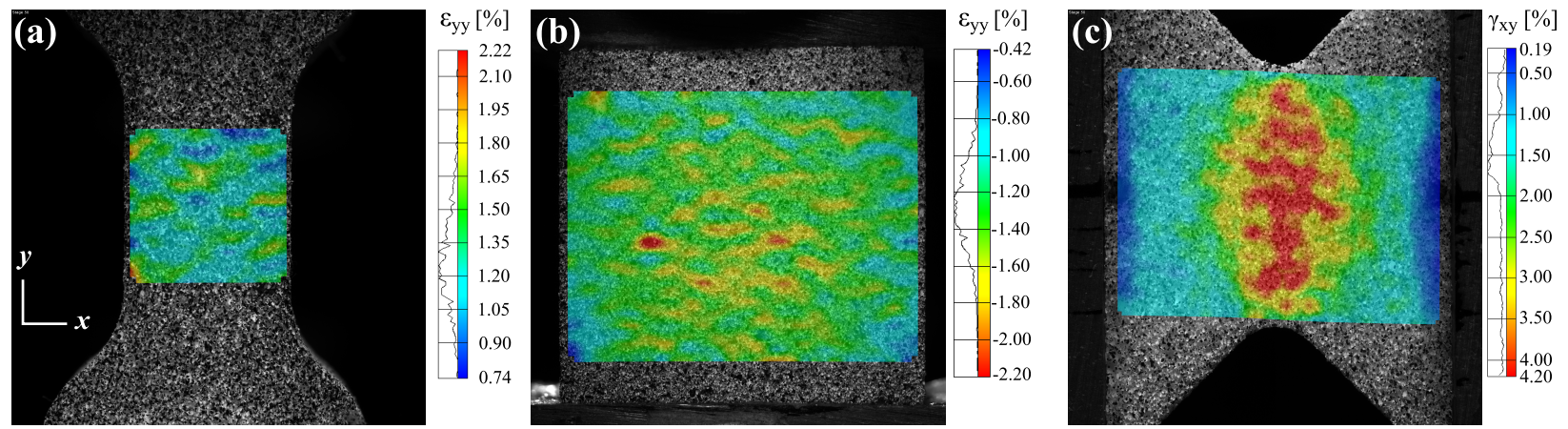

Figure 3. Representative strain fields measured using DIC on a (a) tensile specimen (normal strain in $y$-direction shown), (b) compression specimen (normal strain in $y$-direction shown), and (c) shear specimen (engineering shear strain in $x-y$ plane shown). Loading was applied in the $y$ direction.

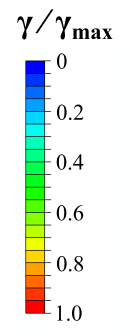

(a)

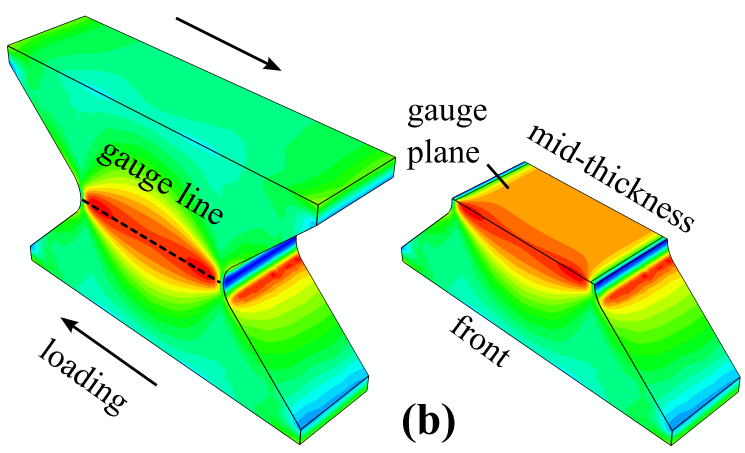

Figure 4. Simulated shear strain distribution in a half-model of a shear specimen (symmetric about the mid-thickness) loaded in the elastic range (a) on the front/back surface, and (b) through the thickness on the plane of the gauge line (cut-away view). 


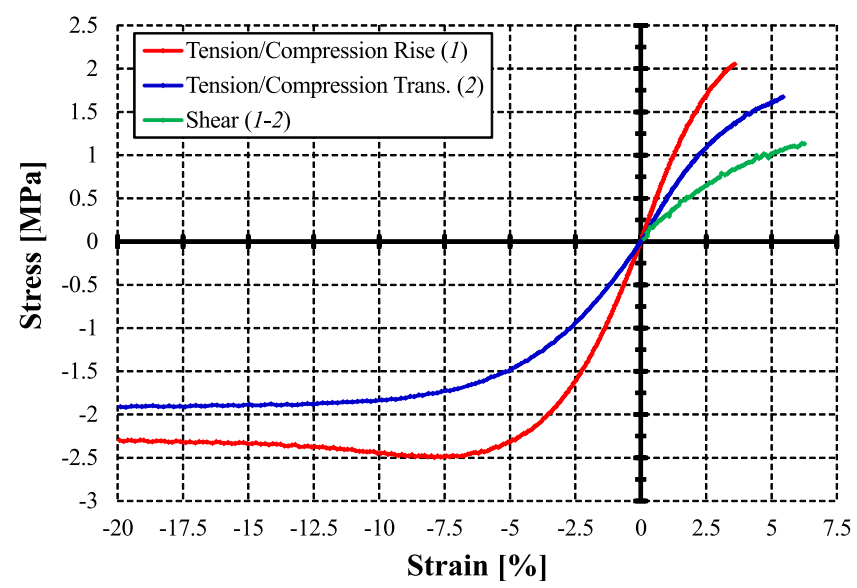

Figure 5. Typical stress-strain curves for pure PU foam $\left(\rho_{\mathrm{f}}=128.0 \mathrm{~kg}-\mathrm{m}^{-3}\right)$ loaded in tension and compression in the rise and transverse directions, and shear in the plane of foaming.

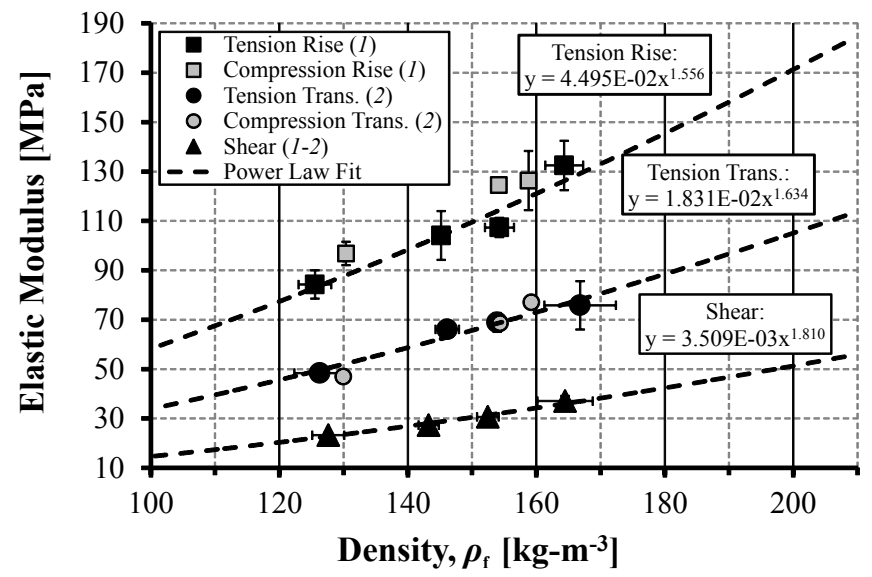

Figure 6. In-plane elastic moduli of pure PU foams at different densities in tension, compression, and shear with power law curves plotted as dashed lines. Each data point represents the average obtained from 5 specimens (except compression, for which 2 specimens were tested) and error bars bound one standard deviation. 


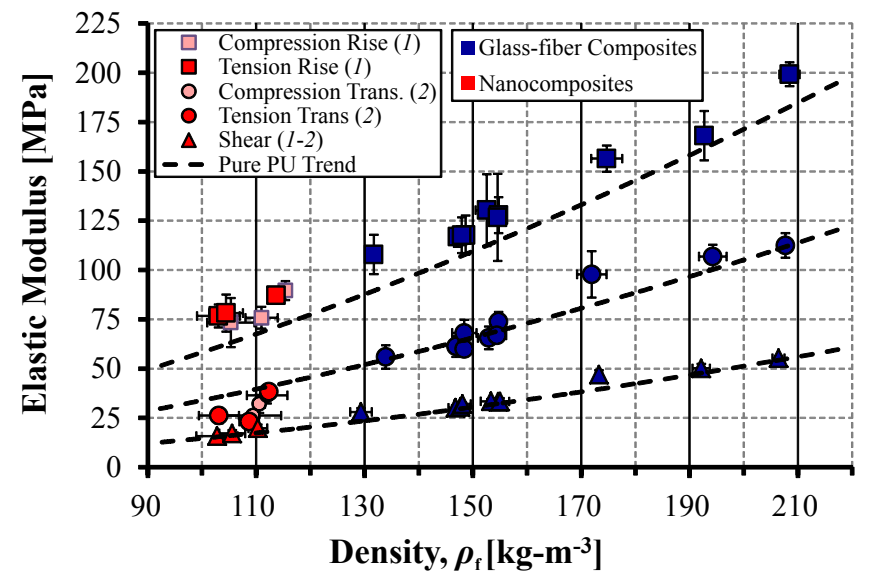

Figure 7. In-plane elastic moduli of glass-fiber ( $\square)$ and nanocomposite foams ( $\square)$ in tension, compression, and shear as a function of density. Each data point represents the average obtained from 4 specimens and error bars bound one standard deviation. 


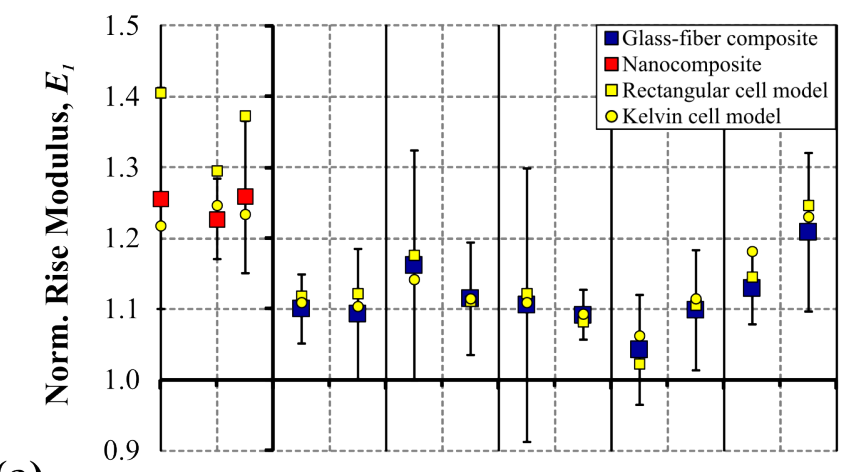

(a)

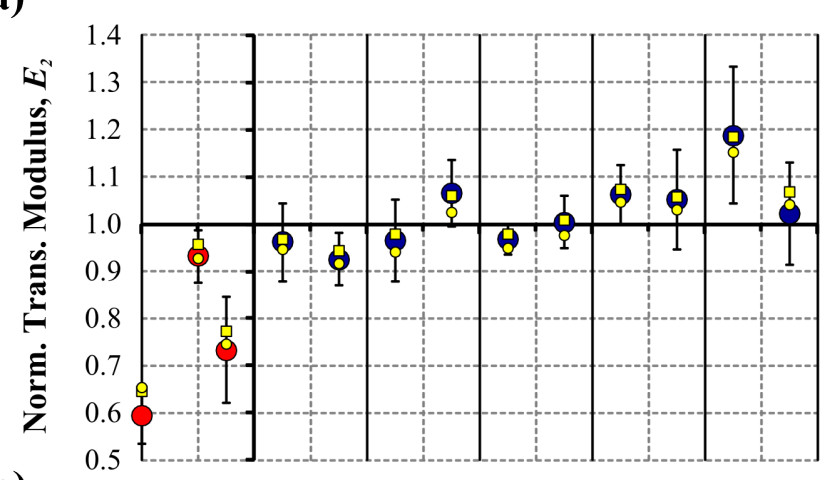

(b)

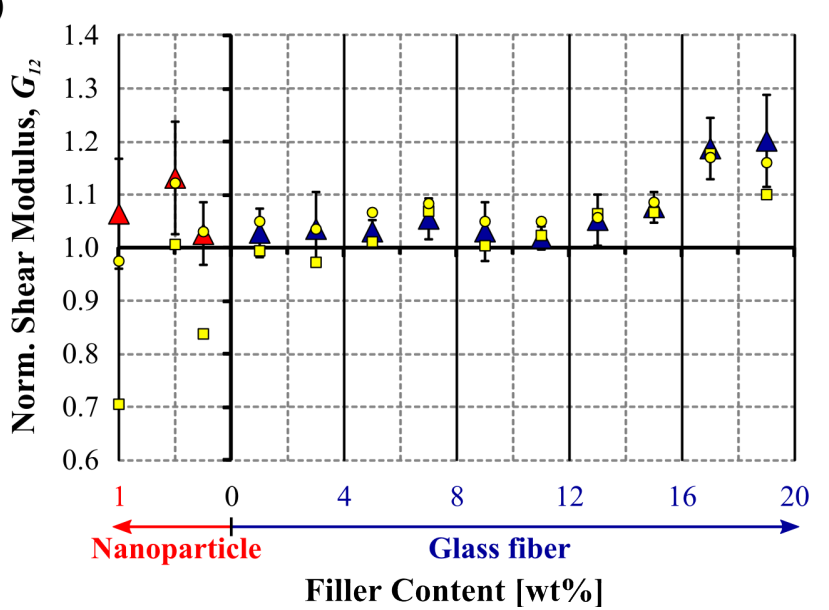

Figure 8. Tensile moduli in the (a) rise and (b) transverse directions, and (c) shear moduli of nanocomposite ( $\square$ ) and glass-fiber foams ( $\square$ ) normalized to the pure PU trend as a function of filler content, with predicted values from Equations (9-11) using the best-fitting $\Gamma$ from both rectangular and Kelvin unit-cell models. 


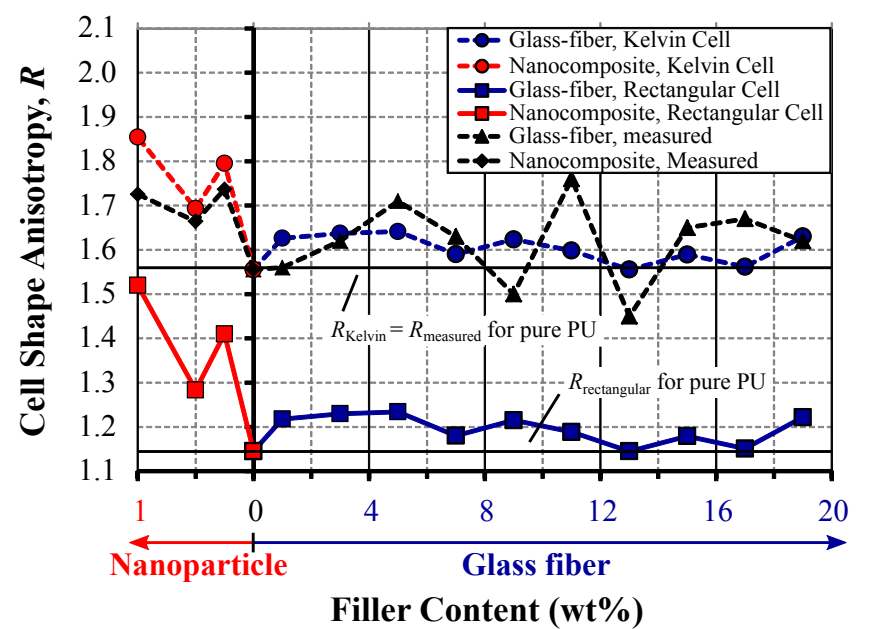

Figure 9. Microscopically measured and predicted (using both rectangular or Kelvin cell models) cell shape anisotropy of pure $\mathrm{PU}(0 \mathrm{wt} \%$ filler $)$ and composite foams as a function of filler content.

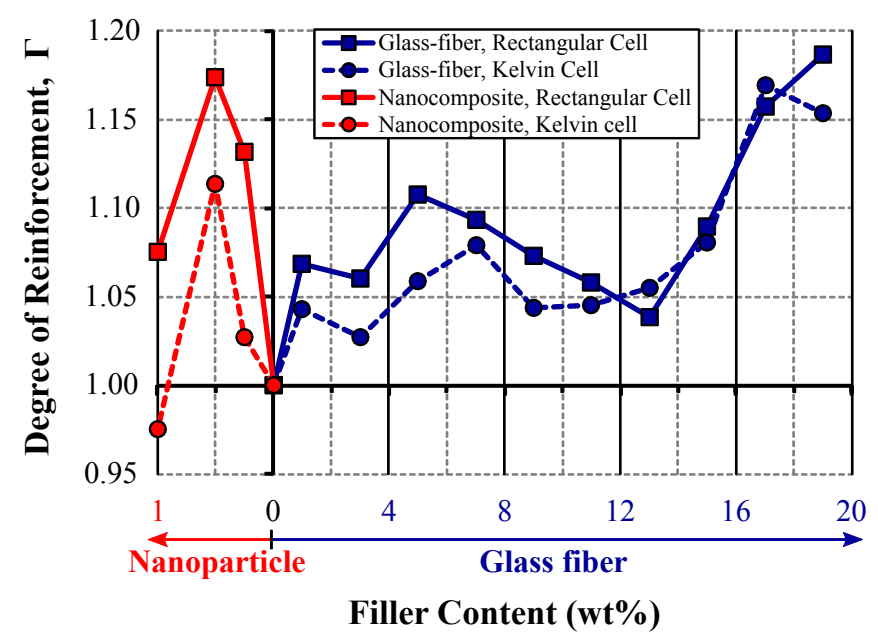

Figure 10. Degree of reinforcement calculated for composite foams using rectangular and Kelvin cellular material models. 